\title{
Os estudos dos esportes na natureza: desafios teóricos e conceituais
}

\author{
Cleber Augusto G. Dias 1 \\ Victor Andrade de Melo 1,2 \\ Edmundo D. Alves Junior ${ }^{3}$
}

https://doi.org/10.5628/rpcd.07.03.358

\author{
1 Instituto de Filosofia e Ciências Sociais \\ Universidade Federal do Rio de Janeiro \\ Brasil \\ 2 Escola de Educação Física e D esportos \\ Universidade Federal do Rio de Janeiro \\ Brasil \\ ${ }_{3}^{3}$ D epartamento de Educação Física \\ Universidade Federal Fluminense \\ Brasil
}

\section{RESUMO}

Este artigo tem por objectivo apresentar e discutir alguns desafios teóricos e conceituais que nos parecem mais prementes para o desenvolvimento de investigações que têm os esportes de aventura na natureza como objectos. Mais especificamente, apresentamos al guns problemas relacionados às conceituações utilizadas e à falta de uma compreensão histórica mais adequada. Esperamos abrir canais de diálogo com outros pesquisadores que se debruçam sobre a temática, bem como buscar mel hor entender as diversas dimensões que configuram o fenómeno na contemporaneidade, não o considerando somente a partir da ideia de ruptura, mas buscando possíveis continuidades do campo esportivo, observáveis desde a modernidade.

Palavras-chave: esporte na natureza, história do esporte, modernidade

\begin{abstract}
Studies of sports in the environment: conceptual and theoretical challenges

This article has for purpose to present and to argue some theoretical and conceptual challenges that we consider more important for the development of researches that have the sports in the environment as object of study. M ore specifically, we argue some problems related to the used conceptualizations and the lack of an adjusted historical understanding. We expect to open channels of dialogue with other researchers, as well as better searching to understand the nowadays dimensions of this social phenomenon, not only considering it from the rupture idea, but searching possible continuities of the sporting field since the modernity.
\end{abstract}

Key-words: sports in the nature, sport history, modernity 


\section{INTRODUÇÃO}

Desde as décadas finais do século $X X$ pode-se observar o aumento das preocupações ecológicas e uma proliferação de discursos ambientalistas. Este conjunto de reflexões e práticas políticas têm tido clara influência no forjar de novos comportamentos, inclusive gerando hábitos de consumo, que vão desde a preferência pela utilização de produtos biodegradáveis até o desenvolvimento de novas formas de cultivo de alimentos, entre muitas outras coisas.

Articulado a esse processo, podemos situar o crescimento, a val orização e a difusão de esportes praticados na natureza.

A nova demanda pela prática de esportes na natureza apresenta aos investigadores o desafio de tentar explicar mais adequadamente esse fenómeno em suas várias dimensões: o que motiva a adesão a esse tipo de actividades? Que sentido cultural assumem no quadro social contemporâneo? Qual a origem desses esportes? Seriam mesmo esportes ou trata-se de uma configuração completamente diferente? Que conceitos nos permitem melhor definir as suas peculiaridades? A despeito de alguns indicadores alvissareiros como o aumento no número de dissertações e teses que versem sobre o tema, percebemos que ainda são parciais os esforços mais sistemáticos no sentido de problematizar algumas questões teóricas e conceituais colocadas pela popularização dessas práticas sociais, fundamentalmente pela ausência de uma compreensão histórica mais profunda. O que tentamos afirmar é que pode ser limitado analisar essas práticas as considerando somente a partir de um ol har contemporâneo, deixando de lado ou minimizando seus antecedentes históricos, abandonando o entendimento de longa duração da própria configuração do campo esportivo.

Este artigo tem por objectivo aprofundar a discussão teórica e conceitual sobre os esportes na natureza, buscando melhor entendêlos historicamente. Esperamos com esse estudo abrir canais de diálogo com outros pesquisadores que se debruçam sobre a temática, bem como buscar melhor entender as diversas dimensões que configuram o fenómeno na contemporaneidade, não o considerando somente a partir da ideia de ruptura, mas buscando possíveis continuidades do campo esportivo, observáveis desde os primórdios do processo de constituição da modernidade.

\section{DIMENSÕES CONCEITUAIS}

É comum falarmos do carácter polifónico do conceito de esporte. As ambiguidades e contradições do objecto geram consideráveis dificuldades no que se refere a sua definição, muitas vezes mesmo impedindo o pacto de acordos mínimos que assegurem estarmos tratando conceitual mente de um fenómeno que compõe uma mesma categoria de análise. No caso das práticas em ambientes naturais, tem-se mesmo questionado se a utilização do termo "esporte" seria adequada para definir estas modalidades. Em linhas gerais, apresenta-se a ideia de que são caracterizadas por motivações, modelos, objectivos, condições e espaços bastante distintos dos "esportes tradicionais"(1).

Queremos deixar claro que não consideramos infundado ou irresponsável tal posicionamento, que encontra inclusive base em muitas posições teóricas acerca do conceito de esporte. Estamos, todavia, questionando determinadas compreensões, notadamente no que se refere a uma certa intransigência à pluralidade de formas de manifestação do esporte e à falta de um entendimento histórico mais profundo acerca dos sentidos e significados do campo esportivo na suas existência concreta desde a modernidade. Antes de discutir sobre a adequação ou não da inserção das práticas corporais na natureza no âmbito do campo esportivo, devemos reflectir sobre o que se considera como "esporte" nessa tentativa de definição. Essa questão, aparentemente simples, pode ser embaraçosa e desconcertante, e é de grande importância, pois a explicitação do que se compreende como "esporte" vai estabelecer categorias conceituais a que se devem remeter a interpretação das experiências a serem analisadas.

A título de exemplificação podemos problematizar uma compreensão comummente propagada: a de que o conceito de esporte refere-se a uma actividade corporal de movimento com carácter de competição. Por esse motivo as práticas corporais na natureza não poderiam ser entendidas como esportivas. Tais assertivas nos permitem discutir dois mal entendidos. O primeiro seria o risco de reduzir o esporte tão somente a uma prática de carácter competitivo no sentido mais stricto. Vale lembrar que há um legado de interpretações, algumas inspiradas no pensamento de Jean-Marie Brohm(2), que tendem a caminhar 
nesse sentido ${ }^{1}$. O esporte seria uma reprodução fiel do mundo do trabalho, sendo os elementos lúdicos praticamente eliminados. O esporte seria "a poesia da hierarquia"; guiado única e exclusivamente pelo princípio de rendimento, norteado fundamentalmente pelas características formais e ocupacionais do campo esportivo.

Essas interpretações encontram ainda eco em uma tradição de análise marxista mais convencional, onde se observa que a difusão massiva do espectáculo esportivo pelas redes de televisão maximizaria a dimensão competitiva em nome de um saciamento da sua própria espetacularização.

Os estudos históricos recentes apontam outras compreensões. Trabal hando na perspectiva dos Estudos Culturais e buscando entender de forma mais matizada e complexa a influência do esporte na formação dos sentidos e significados da modernidade, Melo( 6 , 7) demonstra que foi apreendido como um novo estilo de vida, articulado com a constituição da sociedade do espectáculo, destacando-se pelo seu carácter de festa (relacionado a uma nova dinâmica social de ocupação do espaço público) e por dialogar constantemente com o conjunto de dimensões val orizadas pelas formações culturais específicas. A idéia de circularidade cultural, aponta o autor, parece mais interessante para compreender a formação do campo esportivo.

Sendo assim, devemos questionar os que limitam o esporte a uma reprodução linear da ideia de rendimento, e entendêlo como um fenómeno social mais amplo. Isto não significa uma negação da ideia de competição no esporte. $\mathrm{Na}$ verdade, estamos apenas tentando não menosprezar o seu carácter "Iúdico" (um termo, aliás, muitas vezes utilizado com pouca precisão conceitual) e dimensionar o debate para além do dualismo competição-não competição. Um segundo problema seria a compreensão dos esportes na natureza como de carácter exclusivamente cooperativo, oposto à competição, como se fora um jogo desinteressado, ainda que se admita um progressivo processo de profissionalização. Não é difícil cair nessa armadilha, já que há um efectivo deslocamento do elemento competitivo do outro, do adversário, para si mesmo ou para o próprio meio ambiente, como já demonstraram al gumas pesquisas $(8,9)$.
O que tentamos ponderar e colocar em questão é se essa forma de pensar não parte de uma premissa idealizada, ou até mesmo romantizada, pouco afeita às tensões que se estabelecem ao redor dessas práticas. Desse modo, se apreendidas de maneira linear, as concepções em tela pecariam por desconsiderar a pluralidade de significados inerente ao próprio conceito de esporte, tomando-o como uma prática cultural com sentido unívoco. Ambas insistiriam em um esquema de análise dual, que compartimenta o fenómeno esportivo como sendo, por um lado, uma manifestação do espectáculo e do rendimento, e, por outro, uma expressão do lazer e da ludi cidade².

Cremos que não é possível compreender o esporte dividido entre a pura gratuidade ou a severa seriedade; entre a funcionalidade ou o desinteresse. Podem até existir arranjos das práticas esportivas com predominância de certos aspectos, mas não exclusividade. Ou seja, não há um esporte absoluta e univocamente "competitivo" ou, ao contrário, "cooperativo". Entendêlo no embate e diálogo complexo entre as duas dimensões, sempre simultâneas, parecenos fundamental para nos permitir uma aproximação maior com as ocorrências concretas do objecto. Não podemos nos limitar a uma leitura homogeneizadora do esporte, à luz somente das suas dimensões institucionais, burocráticas ou espectaculares. Ao contrário, devemos buscar uma visão multidimensional, que nos permita entender a complexidade e multiplicidade dos vários aspectos que o compõem.

Trata-se de integrar os aspectos laborais e lúdicos rumo a uma definição mais aceitável de esporte (no sentido de permitir captar com mais acuidade a sua concretude), tal como já propusera o sociólogo Allen Sack(11), que concebeu um modelo que considerava a prática esportiva como um jogo institucional izado que repousa na proeza física, em que proporções variáveis de jogo e trabalho, seriedade e ludicidade, intervêm simultaneamente, dependendo da natureza específica da actividade.

N esse sentido, os esportes na natureza são uma espécie de subcultura esportiva, mas que integram o campo esportivo mais amplo e parece que é assim que devem ser estudados. Ainda que cada modalidade possa ser apreendida em suas especificidades, há sempre referências em comum(12). 
Tomar como premissa, por exemplo, que o surfe e o futebol não fazem parte de um mesmo campo por pertencerem a culturas diferentes é no mínimo exagerado, ainda mais quando consideramos o movimento de esportivização da cultura corporal, onde a distância cultural entre duas modalidades parece diminuir, tornando o compartilhamento de referências simbólicas ainda mais evidente?.

É certo que futebol e surfe - só para permanecermos com esses exemplos - pertencem a "subculturas" diferentes, ao mesmo tempo em que podem comportar uma infinidade de formas. Como bem afirmam Blanchard e Chask: "a variabilidade é, provavelmente, uma característica da maioria dos acontecimentos esportivos em qualquer marco cultural. E toda análise cultural do esporte deve levar em conta essa variabilidade"(11). Mas isso não significa que façam parte de campos diferentes, já que, de maneira mais profunda, compartiIham uma série de dimensões simbólicas.

Sendo uma manifestação cultural, o esporte é dinâmico, sofre mutações no seu desenrolar histórico, acompanhando as mudanças estruturais da sociedade contemporânea. A questão é saber se esse conjunto de modificações do campo esportivo constituise em uma ruptura com sua forma dássica de organização ou se, ao contrário, reproduz-se os seus elementos simbólicos presentes desde o fim do século XVIII. Argumentamos que os esportes na natureza não se constituem em um descontinuidade, da mesma forma que a pós-modernidade não se constitui em uma ruptura com a modernidade, ainda que apresente uma série de novas dimensões que não podem ser negadas e que devem ser cuidadosamente consideradas (13, 14, 15). Devemos então evitar a canonização de uma determinada forma de expressão do esporte (o que pode soar a idealismo e/ ou falta de compreensão histórica), a partir do entendimento de que essa manifestação cultural, como todas as demais, é dinâmica.

Mesmo os encontros de linguagens, típicos da contemporaneidade, ainda que originem novas formas de organização, não destroem as anteriores. As formas de fazer cinema na pós-modernidade, por exemplo, tensionam com os sentidos modernos, mas isso não faz que deixe de ser cinema. A dança contemporânea, continua sendo dança, a despeito das novas dimensões. As artes plásticas na pós-modernidade, do mesmo modo, se confrontam directamente com certas práticas modernas, mas:

Para não incorrermos no erro da própria crítica modernista, é necessário dizer que o contemporâneo não rompe com o moderno, não estabelece com ele um par dicotômico. Ao contrário, a arte contemporânea se entrelaça ao moderno, surge de e graças a sua herança, onde encontrou chão para seus próprios saltos (16).

Assim, as inegáveis mudanças observáveis nos arranjos sociais do esporte na contemporaneidade compõem, nada mais, nada menos, uma nova configuração do fenómeno esportivo, sem com isso descaracterizá-lo como tal. Trata-se de uma adequação (tensa, dialógica e complexa) das práticas esportivas aos novos parâmetros sociais que organizam a vida em sociedade.

Por tudo isso, enfim, acreditamos que é bastante razoável entender a disseminação dos esportes na natureza à luz do processo moderno de esportivização, compreendido aqui como a transformação dos elementos da cultura corporal de lazer em esporte, ou em outros termos, a regulamentação, a decodificação e a institucionalização dos passatempos(17). Falar de definição de conceitos é falar também de uma questão histórica de fundação. Nosso esforço no próximo item será o de entender a partir de que momento a ideia de contacto com a natureza apareceu definida como prática específica, a partir de que momento podemos falar de "esportes na natureza".

\section{DIMENSÕES HISTÓRICAS}

Considerando o quadro que acabamos de delinear, nos parece indispensável o enfrentamento teórico de um segundo desafio: uma compreensão mais aprofundada do contexto histórico em que surge a ideia da busca da natureza para fins esportivos e de lazer. Vale a pena lembrarmos o alerta de Pierre Bourdieu: "U ma das tarefas mais importantes da história social do esporte poderia ser sua própria fundação, fazendo a genealogia histórica da aparição do seu objeto como realidade específica"(18). Importa logo destacar que o comportamento de buscar o meio ambiente como locus para as vivências lúdico-recreativas não é um fenómeno recente. A ideia de val orização e busca da natureza, encarada 
como um refúgio para as mazelas do rápido e desorganizado crescimento das cidades no século XIX, algo articulado com as ideias do primitivismo no âmbito das artes plásticas e do mito do bom selvagem no âmbito da antropologia, vai marcar claramente uma nova organização dos modos de diversão, entre os quais as práticas esportivas(19). Portanto, ainda que os esportes em seu sentido moderno sejam em muito fruto do crescimento de uma cultura urbana, desde suas origens eles também estavam articulados com a ideia de "re-ocupação" do ambiente "natural".

Aqui colocamos o termo "natural" entre aspas porque desde aquele momento é possível identificar que se tratava de uma apreensão bastante idealizada. Naquele instante, "ir à natureza" significava se afastar um pouco dos centros urbanos, comparecendo às praias, rios e bosques localizados nas zonas da periferia, que, aliás, já eram utilizados como local do despejo dos detritos da cidade(19). Nesses locais "selvagens" rapidamente se desenvolveu uma boa estrutura de entretenimento, que permitia aos frequentadores simular "aventuras" e "contactos com o campo" com consideráveis doses de conforto e segurança ${ }^{4}$. Algo bastante similar ao que encontramos nos dias de hoje.

Basta lembrar que, na actualidade, as empresas espe cial izadas oferecem viagens que conciliam aventura e conforto. Algumas delas tornaram-se conhecidas exactamente por oferecer "aventura com estilo". Por exemplo: passeios em Fernando de Noronha regados a champanhe; acampamento no Jalapão, com colchões infláveis, banheiros químicos portáteis e cardápio com crepe flambado; viagens pelos rios da Amazónia onde:

férias na maior floresta do planeta [...] não significa se embrenhar pela mata e passar apertos. As aventuras vistas apenas em livros de história ou em filmes sobre a região podem ser vividas em confortáveis - e divertidos - roteiros de lazer montados por agências e hotéis (21).

Considerando especificamente as actividades que são usual mente reconhecidas como esportes na natureza, podemos dizer que tal prática data, pelo menos, dos idos de 1857, com a fundação do clube de excursionismo britânico. A este se seguiram outras inicia- tivas congéneres: o clube al pino suíço e italiano (1863), o clube al pino alemão (1869), o clube al pino francês (1874), o clube al pino Belga (1883) 5 , e ainda os clubes de montanhismo do Canadá (1906) e dos Estados Unidos (1910). Um pouco mais tarde, o mesmo começa a acontecer na América Latina, com o Centro Excursionista Brasileiro (1919), o Clube Andino de Bariloche (1931) e o clube Andino do Chile (1933).

Lembremos que a organização de clubes é uma das marcas do desenvolvimento do campo esportivo, ai nda que não seja a única a ser considerada. Isso demonstra que já naquele momento existiam preocupações de sistematização da prática. Isso é, tais acontecimentos, mais do que marcos simbólicos, podem significar indícios de um processo de decodificação de um conjunto de mudanças que estavam em curso nas representações colectivas de uma época; uma espécie de expressão mais evidente de reorientações que já estavam em desenvolvimento, sobretudo aquel as que dizem respeito às maneiras de se conceber e de se relacionar com a natureza. A quantidade numérica de iniciativas, a sua amplitude geográfica e o fato de que grande parte desses clubes existe até os dias de hoje é significativo para considerarmos que não se tratava de esforços isolados, mas sim de uma determinada conjuntura. Tratava-se já da constituição de uma subcultura, articulada a um campo em constituição.

Enfim, a institucionalização do hábito de se buscar o "campo" para o divertimento, atribuindo-Ihe usos esportivos e recreativos, inclusive por meio da fundação de clubes, federações e associações esportivas, ilustra as mudanças relacionadas às ideias e concepções acerca da natureza, o que não pode ser descolado do novo modelo de cidade: ainda que muitas vezes tais esportes aconteçam afastados dos grandes centros, parece-nos inegável que eles têm uma profunda articulação com a ideia de urbano(24).

Os novos comportamentos têm relação com um arcabouço de ideias em construção, podendo ser a expressão concreta de um sistema de pensamentos, ainda que a partir de alguns sentimentos imprecisos. Lembremos que Vovelle considera que opiniões podem mesmo se tornar móveis da acção, onde o quadro de ideias funciona como um modelo(25). As convicções de poucos podem se transformar na acção 
de muitos. Revoluções conceituais forjam mudanças nos valores e nos comportamentos humanos.

As mudanças nos sentidos empreendidos ante a ideia de natureza estão profundamente articuladas com a aparição de novos comportamentos, inclusive aqueles hábitos ligados à busca da natureza para o divertimento e para a prática esportiva. E esse processo tem claramente suas raízes no século XIX. Que idéias poderiam explicar o surgimento do hábito esportivo em meio à natureza? Que el ementos podem ser apontados como estímulos preponderantes para a aparição desses novos hábitos e comportamentos esportivos? Que sistema de pensamento pode ser um fator histórico determinante para a compreensão dos esportes na natureza?

As atitudes humanas diante do meio ambiente são histórica e culturalmente construídas, sendo mutáveis e maleáveis(26). Nos momentos precedentes a fundação dos clubes de montanhismo, percebia-se uma postura de receio, de menosprezo e mesmo de repugnância no que se refere às montanhas.

Segundo Robert Mac Farlane, elas eram, até meados do século XVIII, vistas como lugares a serem evitados, não associadas a ideia de beleza ou de prazer. Somente na virada do século XIX é que esses lugares passaram a exercer extraordinário apelo a imaginação: “três séculos atrás, arriscar a vida escalando montanhas era considerado algo insano. Na verdade, mal existia a noção de que paisagens inóspitas constituíam um atractivo [...] No século XVII, os indivíduos mais cultos referiam-se às montanhas em tom de censura"(27). Alan Corbin também demonstrou que sensações e sentimentos desta ordem perpassavam as percepções sobre a praia(28).

No contexto da modernidade, os sentidos e os valores construídos em relação ao "meio ambiente" se desdobram em um conjunto de modelos de apreciação paisagística, uma nova maneira de conceber, de apreciar e de se relacionar com as "paisagens naturais", que por sua vez incidem e se materializam numa série de práticas sociais, incluindo a popularização do hábito de se buscar meios "naturais" para as actividades de lazer, entre as quais as práticas esportivas. Nesse sentido, existe uma forte relação entre o surgimento desse novo sistema de representações colectivas e os primórdios dos esportes na natureza, mais particularmente com o desenvolvi- mento histórico e institucional do montanhismo, inegavelmente o grande precursor desses costumes esportivos.

São muitos os elementos que contribuem para o delineamento deste novo imaginário colectivo, entre os quais destacamos: o crescimento das cidades; a nova organização do trabal ho e a valorização dos momentos de lazer; o higienismo; a noção de pitoresco; a doutrina do sublime e o romantismo; a teologia natural; a difusão da figura do homem acadé mico; a popularização de al gumas ciências e os avanços tecnológicos; tudo articulado com o conjunto de mudanças de natureza económica.

Discorramos sobre o progresso de al gumas ciências, sobretudo o das ciências naturais, como um dos impulsos decisivos para a emergência de uma nova sensibilidade com relação à natureza. O desenvolvimento e a popularização da História Natural, por exemplo, permitiu um maior conhecimento e compreensão do meio ambiente. É importante lembrar que: "por volta da década de 1880, havia várias centenas de sociedades de história natural e clubes de campo no interior que reuniam cerca de cem mil membros"(29).

O desenvolvimento da ornitologia ao longo do sécuIo XIX foi mais um estímulo para que um número crescente de pessoas buscasse os ambientes naturais, à busca da beleza dos pássaros. A geologia, por seu turno, também se prestou a intensificar o fascínio e a curiosi dade pela natureza. Por volta da década de 1860 se proliferava na Europa o chamado turismo geológico, uma modal idade de viagem em que se organizavam visitas guiadas a montanhas e cursos sobre rochas. Esse súbito interesse incentivava o contacto com penhascos e actividades ao ar livre: "o topo da colina e a vista panorâmica ali propiciada tornaram-se um atractivo para pessoas que buscavam 0 lazer"(27).

O montanhismo mais particularmente - que estamos utilizando como exemplo para reflectir sobre o surgimento destes novos costumes esportivos - sempre caminhou pari passu com o progresso científico. Até meados da década de 1920 eram primordialmente fundações científicas que financiavam expedições, como a tentativa de conquista do Everest. Se a revolução científica e tecnológica do século XIX al terou irremediavelmente uma série de atitudes humanas(30), talvez o tenha feito ainda mais particular- 
mente no que se refere aos posicionamentos diante do "natural": a compreensão mais detal hada dos mecanismos de funcionamento da natureza foi paulatinamente aproximando os seres humanos desses antes desconhecidos e hostis espaços. Mais ainda, o avanço científico reduziu a influência e os constrangimentos de natureza religiosa, mais uma importante dimensão tanto para o surgimento de novas formas de diversão quanto para uma nova ocupação e proximidade com o meio ambiente.

A o longo de três séculos, portanto, ocorreu no 0 cidente uma grande mudança de percepção, no que diz respeito às montanhas. Características que outrora levavam a ser desprezadas - altitude, desolação, perigo - passaram a constituir os aspectos mais apreciados(27).

Na medida em que aumentava a capacidade da ciência de revelar mais sobre as estruturas naturais ${ }^{6}$, bem como cresciam rapidamente os complexos urbanos, surgem reacções contra a ideia de desenvolvimento urbano-industrial, ao mesmo tempo em que se desenvolvem iniciativas que propugnavam que uma vida campestre e rural seria um antídoto para os problemas ocasionados pelo ainda recente modelo de organização social, que começava a dar os primeiros sinais explícitos de falência, al go que ficou claro com a Primeira Grande Guerra, marcando o fim da chamada "Belle Époque"7. A depressão económica de 1880 aumentou a agitação e consequentemente o entendimento de que o espaço urbano era agressivo e prejudicial8.

Na verdade, já em 1865 fora fundado na Inglaterra o primeiro grupo ambientalista que reivindicava mais espaços naturais para o lazer da população(26). Alguns governos começaram a reservar áreas naturais para o divertimento público, como o Parque Nacional de Yellowstone (fundado em 1879, nos Estados Unidos), seguido de iniciativas análogas na Austrália (em 1879), no Canadá (com a criação do Parque Banff, em 1888) e na Nova Zelândia (com o Parque Tongarino, em 1894). Àquele tempo, os conceitos de preservação e recreação praticamente se fundiam(29).

Um outro aspecto importante na configuração ou sedimentação dessa nova sensibilidade é o movimento estético do romantismo, com sua típica valorização da curiosidade e da busca por lugares exóticos, desconhecidos, naturais e bucólicos. Ao passo que se difundiam os ideais românticos, podia-se notar uma predilecção pela busca de lugares isolados e de difícil acesso, como os Alpes ou os Pirineus.

H avia motivos práticos para fugir das congestionadas cidades vitorianas. As pessoas que dispunham de recursos tinham uma razão suplementar para sair: desfrutar das belezas da natureza, de preferência em seu estado original. Esse prazer por lugares ermos e selvagens também era novo. John Ruskin viu os A lpes pela primeira vez em 1833, quando tinha quatorze anos - e ficou impressionado. Ao descrever a sensação mais tarde, ele escreveu que sua emoção "devia-se à época: alguns anos antes - menos de um século - nenhuma criança se preocuparia em dar atenção às montanhas". A conclusão de Ruskin é importante. 0 movimento romântico mudou não só os princípios artísticos, mas também as sensibilidades das pessoas. A paisagem das montanhas e do litoral, antes desprezada, passou a ser procurada como uma gratificante experiência estética(32).

A busca da natureza também era incentivada pelo progressivo aumento das al ternativas de lazer no fim do século XIX, onde as viagens apresentavam-se como uma importante opção. Nos passeios de férias ou de fim de semana vivenciava-se al go relativamente novo até então: a possibilidade de se obter prazer pura e simplesmente pelo conhecimento de outros lugares. Certamente a melhora e o desenvolvimento de novos meios de transporte (a bicicleta, o trem, o carro e posteriormente o avião), al go que está articulado com o já discutido processo de revolução científica-tecnológica do século XIX, aumentou consideravelmente as possibilidades de mobilidade social e, em al guma medida, incentivou (e mesmo permitiu) o desejo de se conhecer novos lugares.

No final dos anos 1880, lugares avaliados como símbolos de belezas misteriosas e selvagens eram invadidos por andarilhos em busca dos prazeres oferecidos pela natureza. Aos poucos, como nos relata Eugen Weber, "os penhascos deixavam de produzir maus espíritos e passavam a produzir moedas brilhantes deixadas por turistas curiosos"(23). Não por acaso as estações de montanha foram os primeiros destinos de viagem a criar centros de informações turísticas. Desde muito precocemente já se observava a organização de um mercado ao redor dessas práticas. 
Não se tratava exclusivamente da busca pela nature za em si. Nessas viagens já se destacava o interesse pelo ar puro, mas também pela ginástica, pela aventura e pelas proezas físicas. Os lugares destinados às viagens de lazer estavam atrelados, graças ao forte apelo do discurso higienista da época, a virtudes medicinais, que quase sempre eram apresentadas como remédios para os males da vida urbana, notadamente o estresse e a poluição.

Enfim, os fundamentos mais elementares da ideia de busca da natureza como fonte de prazer e de divertimento, marcas do surgimento dos esportes na natureza, já estavam postos no século XIX. Naquele momento tais práticas já estavam organizadas em modelos bastante semelhantes ao dos dias de hoje. Obviamente que hodiernamente tais esportes apresentam uma série de novas peculiaridades, dialogando com as diversas dimensões socioculturais contemporâneas. Contudo não parecem se apresentar como ruptura com os formatos multifacetados do campo esportivo. Antes parecem mais desdobramentos desse processo contínuo e tenso de configuração.

\section{À GUISA DE CONCLUSÃO}

A crítica central desse estudo é a de que comummente os trabal hos académicos que têm os esportes na natureza como objecto de investigação desconsideram ou fazem uso parcial e controvertido de reflexões de natureza histórica. Isso pode ser responsável pela construção e utilização de conceitos limitados no sentido de operar interpretações mais amplas e complexas acerca da presença concreta dessas práticas no tempo e no espaço, inclusive no contexto da sociedade contemporânea.

Ao propormos que os princípios de organização dos esportes na natureza já estavam bem defini dos desde o século XIX não estamos negando a actualidade que a interface entre esporte e meio ambiente assume nos dias de hoje. Tampouco estamos desconsiderando as reconfigurações do campo esportivo. A questão central é que os elementos de descontinuidade, de ruptura e de inovação, devem ser analisados articuladamente com as "estruturas de longa duração"(33). Estamos, portanto, defendendo a ideia de que as inovações nos hábitos esportivos que os esportes na natureza trazem consigo se inserem em um longo processo de desenvolvimento histórico, que deve ser seriamente considerado para fins de uma compreensão mais ampliada dos seus sentidos e significados no quadro contemporâneo.

Isso está profundamente articulado com o entendimento teórico e conceitual que vai se atribuir a estas práticas. Não estamos propondo respostas definitivas. Ao contrário, conforme mencionamos no início deste trabalho, nosso objectivo foi o de chamar a atenção para alguns desafios que nos parecem mais prementes e abrir um debate e canais de diálogo nessa direcção.

\section{CORRESPONDÊNCIA}

\section{Cleber Augusto Gonçalves Dias}

Rua Otávio de Souza, lote 12 , quadra D, casa 1

Campo Grande

Rio de Janeiro, RJ - Brasil. 23087 - 030

E-mail: cag.dias@bol.com.br 
NOTAS

1 Uma discussão sobre o pensamento desse autor pode ser encontrada nos estudos de Marcelo Proni( ${ }^{(3)}$ e de Richard Giulianotti $(4,5)$

2 Marco Stigger ${ }^{(10)}$ alerta para o perigo teórico-metodológico de negligenciarmos as apropriações microsociais do fenómeno, o que pode conduzir a um enfoque exagerado nos grandes eventos, distanciando-se do espaço concreto e cotidiano onde o esporte também acontece.

3 Tendência que se manifesta no impulso em dotar as manifestações corporais de um caráter competitivo e espetacularizado tal como ocorre, já há al guns anos, com o montanhismo, onde existe um movimento que tenta enquadrar o esporte nos moldes olímpicos. Vale destacar que tal movimento influência mesmo outros típicos de manifestações, algo claro, por exemplo, nas "olimpíadas de matemática" ou "jogos olímpicos de arte".

4 Por exemplo, no início do século XIX a rainha Maria Antonieta frequentava uma casa de verão, em Versalhes, que simulava uma aldeia normanda e era dotada de vários artifícios para imitar uma paisagem natural. Nas duas viagens anuais que fazia ao local, tentava "fazer de conta que era uma camponesa, tomando sorve te numa mesa de mármore, colhendo flores no jardim ou segurando uma vara de pescar na beira do lago artificial" (20).

${ }^{5}$ Alguns países da Europa têm nos esportes de montanha uma de suas principais tradições esportivas. A mentalidade esportiva alemã, por exemplo, esteve durante muitos anos ligada quase que exclusivamente a ginástica, as marchas e ao al pinismo(22). Na França, depois da fundação do seu primeiro clube al pino, a prática rapidamente se popularizou. O modelo associativo francês não era limitado a escaladores como acontecia na Inglaterra(23) e isso certamente incentiva o acesso.

Actualmente, de acordo com os dados da Federação Francesa de clubes de al pinismo e montanhismo, o país conta com 240 clubes e 89.000 membros associados.

${ }^{6}$ Desempenhando grande influência, deve-se destacar a publicação da obra "A origem das espécies", de Charles Darwin em 1859. ${ }^{7}$ Nesse sentido, a minuciosa análise das condições urbanas dos operários ingleses, empreendida por Friedrich Engels em "A situação da classe trabalhadora na Inglaterra", teve grande impacto. A organização de movimentos dos trabal hadores contribuiu para explicitar as contradições do sistema. Uma análise do período pode ser encontrada no livro de Eric Hobsbawn(31). ${ }^{8} \mathrm{Em} 1800$, Londres já era a maior cidade do mundo, com um milhão de habitantes. Entre 1800 e 1850, a população da Inglaterra mais que dobrou e no fim do século a capital londrina apresentava uma população de cinco milhões de habitantes. Essas condições impulsionavam o aparecimento de protestos e lamúrias acerca dos problemas urbanos. Quem visitava a Londres do século XIX, "achava os congestionamentos de trânsito um escândalo. 0 fedor de urina e estrume dos cavalos era insuportável"(32). 


\section{REFERÊNCIAS BIBLIOGRÁFICAS}

1. Betrán JO (2003). Rumo a um novo conceito de ócio ativo e turismo na Espanha: as atividades físicas de aventura na natureza. In: Marinho AM, Bruhns H (orgs.). Turismo, lazer e natureza. São Paulo: Manole, 157-202.

2. Brohm JM (1978). Sport: a prison of measured time. Londres: Pluto.

3. Proni MW (2002). Brohm e a organização capitalista do esporte. In: Proni MW, Lucena R (orgs.). Esporte: história e sociedade. Campinas, SP: Autores Associados,.31-62.

4. Giulianotti R (2004). Sport and modern social theorists. Nova York: Palgrave Macmillan;

5. Giulianotti R (2005). Sport: a critical sociology. Cambridge: Polity.

6. Melo VA (2006). A presença do esporte e do lazer em obras de arte. U ma análise comparada de impressionistas e futuristas. Fênix 3: no prelo.

7. Melo VA (2006). Esporte e cinema: diálogos. Rio de Janeiro: Aeroplano.

8. Costa VLM (2000). Esportes de aventura e risco na montanha. São Paulo: Manole.

9. Souza FR (2004). 0 imaginário no rafting. São Paulo: Zouk.

10. Sttiger MP (2002). Esporte, lazer e estilos de vida: um estudo etnográfico. Campinas: Autores Associados/CBCE.

11. Apud. Blanchard K, Cheska A (1986). A ntropologia del deporte. Barcelona: Bellaterra: 35.

12. Dias C, Alves Junior E (2006). Conceptual notes regarding the sports in nature. The FIEP bulletin 76: 141-144.

13. Canclini NG (2003). A globalização imaginada. São Paulo: Iluminuras.

14. Canclini NG (2005). Consumidores e cidadãos. Rio de Janeiro: Editora da UFRJ,.

15. Jamenson $F$ (2004). Espaço e imagem. Rio de Janeiro: Editora da UFRJ.

16. Canongia $L$ (2005). 0 legado dos anos 60 e 70. Rio de Janeiro: Jorge Zahar: 89-13

17. Elias N, Dunning E (1992). A busca da excitação. Lisboa: Difel.
18. Bourdieu P (1983). Como é possível ser esportivo? In: Bourdieu $\mathrm{P} Q \mathrm{Q}$ uestões de Sociologia. Rio de Janeiro: Marco Zero.207-220: p. 137 - 15

19. Melo VA, Peres FF (2005). Lazer, esporte e cultura urbana na transição dos séculos XIX e XX: conexões entre Paris e Rio de Janeiro. Logos.12: 75-92.

20. Rybczynski W (2000). Esperando o fim de semana. Rio de Janeiro: Record: 149 - 17

21. O Globo (2006). Na selva, mas sem sustos. Rio de Janeiro: Caderno Boa Viagem, p.12-15, 26 de janeiro de 2006.

22. Silva FCT (2006). Futebol: uma paixão coletiva. In: Silva FCT, Santos RP (orgs.). M emória Social dos esportes. v. 2. Rio de Janeiro: Mauad/Faperj, 15-32.

23. Weber E (1988). França fin de siecle. São Paulo: Companhia das Letras: 236- 20.

24. Dias C, Alves Junior E (2006b). Esporte, cidade e natureza. Licere 9: 37-53.

25. Vovelle M (1987). Ideologias e mentalidades. São Paulo: Brasiliense.

26. Foladori G, Taks J (2004). Um olhar antropológico sobre a questão ambiental. M ana 10: 323-348.

27. MacFarlane R (2005). M ontanhas da mente. Rio de Janeiro: Objetiva: 23 - 141- 26 - 24

28. Corbin A (1989). 0 território do vazio. São Paulo: Companhia das Letras.

29. McCormick J (1992). Rumo ao paraíso. Rio de Janeiro: Relume Dumará: 23.

30. Costa AM, Schwarcz LM (2000). 1890 - 1914: no tempo das certezas. São Paulo: Companhia das Letras.

31. Hobsbawn EJ (1998). A era dos impérios. Rio de Janeiro: Paz e Terra.

32. Rykwert J (2004). A sedução do lugar. São Paulo: Martins Fontes: 58 - 29.

33. Braudel F (1978). Escritos sobre história. São Paulo: Perspectiva. 